\title{
The art of medicine
}

COVID-19, online shaming, and health-care professionals

Stigma and shame are common features of pandemics. The stigma associated with disease can be experienced as shame by those who spread it. In almost all human cultures, there is shame attached to being "contaminated", to the vulnerability inherent in illness, and to potentially spreading a disease to others. As previous pandemics have taught us, coming into contact with, or being associated with, a highly infectious and potentially deadly disease has social consequences. Hence, it is no surprise that stigma and shame have developed around COVID-19. Although there have been outpourings of support and admiration for health-care workers for their work in this pandemic, health professionals have been among those directly affected.

In previous epidemics, health-care workers have been shunned, feared, and treated with suspicion. Doctors on HIV wards in the UK during the 1990s described how anxieties around "contamination" led colleagues in other specialties to stigmatise their work as devalued and shameful. In an outbreak of Ebola virus disease in Uganda in 2000-01, one nurse heartbreakingly recalled, "Our clothes were burned, and our children kept away from us, our families shunned us and were afraid of us." Health-care workers on the front line of the COVID-19 response have similarly been victims of stigmatisation and shaming, sometimes leading to violence and abuse. The fear of contamination and of spreading the virus has led to nurses in the UK being attacked on the street; care workers being verbally abused in supermarkets; and paramedics being evicted from their homes. Worldwide, doctors have been shamed and bullied for refusing to work without adequate personal protective equipment (PPE), while the wartime rhetoric deployed by some politicians set up pernicious expectations of personal sacrifice for health professionals. What seems to set COVID-19 apart from earlier events is the extent of shaming that has been fuelled by social media use. Online shaming and online outrage in this pandemic have channelled fears and uncertainties about the disease, and frustrations with disruptive public health measures put into place to control COVID-19. Unfortunately, doctors, along with other health-care workers have become the targets of online shaming pile ons.

Among those subjected to public shaming in the pandemic were an Australian general practitioner, Chris Higgins and Jean-Robert Ngola, a physician in New Brunswick, Canada. Higgins had continued to see his patients in his Melbourne practice while he had what he thought was a mild cold after a trip to the USA, before he tested positive for SARS-CoV-2. Ngola was accused of failing to self-isolate on his return from crossing the border with Quebec. Such cases occurred in the context of global medical cultures of overwork, in which health-care professionals may be expected to go to work when they are unwell and lambasted if they take time off. Both physicians were singled out by politicians and although neither were mentioned by name, local news sources and social media accounts identified them, and they were subject to online shaming. Ngola's shaming was further inflected with racist vitriol. Charges against Ngola of 
breaching the provincial Emergency Measures Act were eventually dropped but these events underscored his precarious status as a racialised doctor.

In the UK, as elsewhere, the online shaming directed at doctors has shifted its focus throughout the pandemic, from shaming health-care professionals for their status as potential "super spreaders", to discrediting them as witnesses. Shortly before an appearance on the BBC's television programme Question Time in January, 2021, the palliative care doctor and writer Rachel Clarke tweeted the day's number of COVID deaths, swiftly followed by this pre-emptive message: "And before the deluge of abuse begins, don't bother. I am seeing these poor human beings in their final days, hours and moments of life. I am seeing it-day after day after day-and it's utterly, horribly heartbreaking." Clarke and other health professionals have been shamed, harassed, and threatened by COVID-19 sceptics who continue to allege that the virus is a hoax and that doctors are party to a deception to fool or mislead the public. While some physicians have faced online shaming and abuse for potentially spreading the virus or falling short of the expectations of inhuman infallibility routinely imposed on doctors, by contrast the shaming that Clarke referred to in her Tweet, is directed towards what doctors are seeing, witnessing, and saying.

Public shaming used to take place in the public square, where members of one's immediate community would mete out judgment and punishment for social and moral transgressions. From the public square, to newspapers, to television, nowadays public shaming has moved primarily to the internet. This move to the online arena is not merely a shift in the medium of shaming. It creates a whole new set of conditions for its occurrence. The internet, a domain with ample opportunity for anonymity, lacks the geography and temporality of previous sites of public shaming. As the philosopher Bonnie Mann has described in relation to online gender-based shaming, the "scene of shame" has changed dramatically with the internet. Online shame is unbounded by space and time, it can follow an individual everywhere and indefinitely. Shaming is transformed from something fleeting into a permanent record of a mistake or transgression (real or alleged): a "digital scarlet letter", as Dean Levmore and Martha Nussbaum describe it. In this way, online shaming can amplify a minor transgression into a major life-changing incident. It can generate vitriol, abuse, and hate for an entirely false accusation, leading nonetheless to reputational damage and personal harm.

While online shaming usually stems from two primary motivations, rectification (righting some perceived wrong) and cruelty (revenge, degradation, or an attack for personal reasons), these are by no means mutually exclusive. Online shaming that is used to target individuals for actions that are deemed "undesirable" or "unacceptable" can also involve a cruel attack in order to further personally 'punish' an individual for this transgression (real or alleged). These dynamics of rectification and cruelty online are increasingly intruding into the lives of some health-care professionals. A shaming response for a perceived mistake, can rapidly be transformed into cruel attacks on one's character, family, reputation, and livelihood, and on occasion with threats of violence and death. 
The resurgence in 2020 of the hashtag \#NoToDoctorShaming on Twitter highlights the increasing prevalence of this phenomena, where doctors, in particular, are often held up to super-human standards that demand infallibility. Common human occurrences, such as making mistakes, falling sick, displaying emotion, or just needing sleep while on the job are potential opportunities for shaming. Working on the front line of medicine, health-care workers are often blamed, or are perceived to be responsible for system-wide problems such as staff shortages, short appointment times, insufficient bedspace, PPE shortages, waiting lists, or limited treatment options. Such pressures are compounded by the emotional and physical strain that comes with long working hours and having high case loads, all of which have been exacerbating during the COVID-19 crisis.

Because online shaming is often unbounded by time, place, and scale, its effects are unpredictable: it may dissipate quickly with no ill effects; it may lead to a shaming backlash; or it may result in a shaming pile on that has devastating and long-lasting effects. While shaming an individual can sometimes lead to positive change, it is more likely to have negative consequences and could lead to defensiveness, anxiety, social withdrawal, or adverse effects on one's mental health. As testimonies by victims of online shaming demonstrate, online shaming can be life-destroying. It can lead to unemployment, reputational damage, and compromised social and intimate relationships. The online shaming of some health professionals during the COVID-19 pandemic exacerbates a culture of "fear and shame" that already circulates in health care for medical professionals. Research has shown health-care staff reporting "feelings of fear, being blamed, shamed or even dismissed" in their workplaces. It also highlights the broader shaming culture that has become commonplace in the public sphere.

Although some health professionals are the recipients of online shaming, others have used social media as a social and political tool. Australian general practitioners expressed their support for Higgins on social media after his online shaming. Clarke and others are using their voices on Twitter and in the media to highlight poor public health policy and to call to account those responsible. But, the unbounded nature of online shaming means that even these "good" uses of shaming may risk exacerbating an already fraught situation. The problem with shaming, whether in medicine or in politics, is that its effects are unpredictable. We can never be sure how it will land and what effects it will have.

\section{*Luna Dolezal, Arthur Rose, Fred Cooper}

Wellcome Centre for Cultures and Environments of Health, University of Exeter, Exeter, EX4 4QH, UK I.r.dolezal@exeter.ac.uk

Research that has informed this essay was funded in part by the Wellcome Trust [217879/Z/19/Z] and was also supported by the Arts and Humanities Research Council, grant number: AH/V013483/1. 